\title{
Pleth variability index or stroke volume optimization during open abdominal surgery: a randomized controlled trial
}

\author{
Hans Bahlmann ${ }^{1,2^{*}} \mathbb{D}$, Robert G. Hahn ${ }^{3}$ and Lena Nilsson ${ }^{1,2}$
}

\begin{abstract}
Background: The impact of Goal Directed Fluid Therapy (GDFT) based on the non-invasive Pleth Variability Index (PVI) on clinical outcome after abdominal surgery has only sparingly been explored. The purpose of this study was to compare the effect of intraoperative GDFT guided by PVI to a control group using esophageal Doppler on the incidence of complications and length of hospital stay after major abdominal surgery. We hypothesized that there would be no difference between the groups.
\end{abstract}

Methods: This was a randomized controlled trial in a Swedish university hospital between November 2011 and January 2015; 150 patients scheduled for open abdominal surgery lasting $2 \mathrm{~h}$ or more were included. Exclusion criteria included hepatic resection or severe cardiac arrhythmia. The patients were randomized 1:1 to either the intervention group or the control group. The intervention group received intraoperative GDFT by administering fluid boluses of $3 \mathrm{ml} / \mathrm{kg}$ tetrastarch aiming at a PVI value below 10\%, while GDFT in the control group aimed for optimization of stroke volume as assessed with esophageal Doppler. Blinded observers assessed complications until postoperative day 30 using pre-defined definitions, as well as length of hospital stay.

Results: One hundred and-fifty patients were randomized and 146 patients were available for the final data analysis. Median duration of surgery was $3 \mathrm{~h}$. A total of 64 complications occurred in the PVI group ( $N=74)$ and 70 in the Doppler group $(N=72)(p=0.93)$. Median (IQR) length of stay was $8.0(8.0)$ days in the PVI group and $8.0(9.5)$ in the Doppler group $(P=0.57)$.

Conclusions: No difference in clinical outcome, as defined by number of postoperative complications, and length of hospital stay, was found when goal directed fluid therapy was applied using PVI as an alternative to esophageal Doppler. PVI appears to be an acceptable alternative to esophageal Doppler for goal directed fluid therapy during major open abdominal surgery.

Trial registration: Clinicaltrials.gov NCT01458678. Date of first registration October 20, 2011.

Keywords: Doppler ultrasonography, Fluid therapy, Laparotomy, Photoplethysmography, Stroke volume, Complications

\footnotetext{
* Correspondence: hans.bahlmann@regionostergotland.se

${ }^{1}$ Department of Medical and Health Sciences, Linköping University, University

Hospital, 58185 Linköping, Sweden

${ }^{2}$ Department of Anesthesiology and Intensive Care, Linköping University,

University Hospital, 58185 Linköping, Sweden

Full list of author information is available at the end of the article
}

(c) The Author(s). 2018 Open Access This article is distributed under the terms of the Creative Commons Attribution 4.0 International License (http://creativecommons.org/licenses/by/4.0/), which permits unrestricted use, distribution, and reproduction in any medium, provided you give appropriate credit to the original author(s) and the source, provide a link to the Creative Commons license, and indicate if changes were made. The Creative Commons Public Domain Dedication waiver (http://creativecommons.org/publicdomain/zero/1.0/) applies to the data made available in this article, unless otherwise stated. 


\section{Background}

The incidence of postoperative complications after major abdominal surgery is increased by both overly restricted and overly liberal fluid administration [1]. Goal directed fluid therapy (GDFT) aims to determine the optimal amount of fluid for an individual patient, and meta-analyses point out its clinical benefits, especially in patients not participating in an enhanced recovery program [2, 3]. Hemodynamic optimization has mostly been guided by stroke volume, commonly measured via esophageal Doppler, or by dynamic parameters such as stroke volume variation, pulse pressure variation or the pulse oximetric Pleth Variability Index (PVI), which all are based on cardiopulmonary interactions.

The latter techniques have been advocated because they are easier to apply and of similar clinical value as methods aiming at optimization of stroke volume [3] despite certain methodological issues, such as the influence of tidal volume, respiratory and heart rate ratio, spontaneous breathing, chest wall compliance, arrhythmia and abdominal pressure $[4,5]$. The impact of PVI on clinical outcome in terms of postoperative complications or length of stay is sparingly described in randomized studies [6-8]. PVI guided bolus doses were compared either to a fluid regimen using bolus doses based on mean blood pressure $[6,7]$ or on Doppler measured stroke volume changes [8]. Although no difference on the incidence of postoperative complications or length of stay was reported, the studies are small and two of them restricted to colonic surgery. We found it of interest to further evaluate the effect of PVI on clinical outcome in abdominal surgery.

We designed a randomized controlled trial comparing patients treated with fluid optimization guided by PVI with control patients who received stroke volume optimization guided by esophageal Doppler.

This is a planned secondary analysis of a study primarily designed to analyze differences in intraoperative fluid use. Primary outcome measures were the amount of colloid used for optimization of fluid status and the concordance between different methods for assessing preoperative dehydration. These results have been published elsewhere $[9,10]$ and included the first half of the study cohort (75 patients). The present article focuses on clinical outcome in the whole cohort of 150 patients, as quantified by number of postoperative complications up to 30 days after surgery and length of hospital stay, both of which were designated as secondary outcome measures in the study protocol.

We hypothesized that there would be no difference between the groups regarding these parameters.

\section{Methods}

Ethical approval was obtained from the Regional Ethical Review Board in Linköping in March 2011 (2011/ 101-31), as was written informed consent from all included patients. The study was prospectively registered at clinicaltrials.gov (NCT 01458678).

This single-blind randomized study was performed at University Hospital Linköping, a 600-bed tertiary care facility in Sweden. As previously described [9], adult patients, ASA class 1-3, planned for elective open abdominal surgery with an expected duration of at least $2 \mathrm{~h}$ were screened for inclusion. Exclusion criteria included hepatic resection, severe forms of cardiac arrhythmia, planned central hemodynamic monitoring for cardiac reasons, enrollment in another interventional study or unavailability of research staff.

\section{General management}

Patients were recruited from different departments (gynecology, surgery and urology) and therefore preoperative management with regard to fluids and antibiotics followed departmental routines, which could include an explicit enhanced recovery program. After siting a thoracic epidural catheter (when indicated), general anesthesia was induced using fentanyl and propofol or thiopental and maintained using sevoflurane and iterated doses of fentanyl. Intubation was facilitated with rocuronium or succinylcholine. Epidural analgesia was started before the surgery commenced using a continuous infusion of a mixture of bupivacaine, fentanyl and epinephrine supplemented by bolus doses if indicated. All patients were ventilated using a Volume Control mode with a standardized tidal volume of $7 \mathrm{ml} \mathrm{kg}^{-1}$ ideal body weight [11].

A maximum of $500 \mathrm{ml}$ of tetrastarch, either Venofundin (B Braun Medical AB, Danderyd, Sweden) or Volulyte (Fresenius Kabi AB, Uppsala, Sweden), could be infused during the epidural catheter placement and the subsequent induction of anesthesia. Both groups received a baseline infusion of $2 \mathrm{ml} \mathrm{kg}^{-1} \mathrm{~h}^{-1}$ (actual body weight) of a $2.5 \%$ buffered dextrose solution containing $70 \mathrm{mmol} \mathrm{l}^{-1}$ sodium, $45 \mathrm{mmol} \mathrm{l}^{-1}$ chloride, and $25 \mathrm{mmol} \mathrm{l}^{-1}$ acetate (Glukos Braun $25 \mathrm{mg} \mathrm{ml}^{-}$ ${ }^{1}$ with buffer (B Braun Medical AB, Danderyd, Sweden) during surgery. Correction for additional crystalloid fluids given (e.g. antibiotics) was not made. Up to $1000 \mathrm{ml}$ of Ringer's acetate could be infused during surgery to compensate for preoperative dehydration or increased non-hemorrhagic intraoperative fluid loss. Bleeding was replaced 1:1 with a colloid (tetrastarch, albumin 5\%, plasma, packed red blood cells or platelets). Infusions with vasoconstrictors (norepinephrine or phenylephrine) and/or inotropes (dobutamine) were used at the discretion of the responsible anesthetist.

\section{Study groups}

Patients were recruited and randomized 1:1 by $\mathrm{HB}$ or LN, using opaque envelopes prepared by a research nurse from a computerized randomization procedure [12], to receive intraoperative fluid optimization guided 
by either the pulse oximetric PVI or esophageal Doppler. The PVI was monitored using a Radical-7 Pulse CO-oximeter (Masimo Corporation, Irvine, California, USA) with PVI software (Version SET V7.8.0.1), a re-usable sensor (R2-25r) and a disposable adhesive (R2-25a). The sensor was placed on the middle or index finger of either hand and was covered to avoid room light interference. The placement of a blood pressure cuff on the same arm was avoided.

The esophageal Doppler measurements were performed using a CardioQ apparatus (Deltex Medical, Chicester, United Kingdom) equipped with a DP12 probe, and the signal was averaged over 20 cardiac cycles. In both groups, fluid optimization was initiated after induction of general anesthesia and undertaken by infusing $3 \mathrm{ml} \mathrm{kg}^{-1}$ actual body weight (up to $250 \mathrm{ml}$ ) of tetrastarch intravenously during 3-5 min, using a $50 \mathrm{ml}$ syringe. As described previously [9], during the first half of the study (patients 1-75), in which the concordance between the methods was studied, all patients were monitored with both PVI and esophageal Doppler. Only the allocated monitor was visible to the responsible anesthetist. For the second part (patients 76-150) only the allocated monitor was used.

\section{Fluid bolus algorithms}

In the PVI group, a fluid bolus was given if PVI $\geq 10 \%$. The cut-off value of $10 \%$ was chosen based on a previous report [13]. If the PVI 5 min after the fluid bolus fell below $10 \%$, no more fluid was given. If the PVI 5 min after the fluid bolus was still $\geq 10 \%$ but had decreased, a repeat fluid bolus was given. Fluid boluses were repeated until the PVI fell below $10 \%$ or did not decrease at all. During surgery, additional optimizations were undertaken in the same way whenever the PVI increased to $\geq 10 \%$. In order to have at least one fluid bolus available in each patient for analyzing the performance of PVI compared to Doppler during an optimization and in analogy with the Doppler group [9], a fluid bolus was given to all patients in the PVI group after induction of anesthesia, irrespective of the PVI value.

In the Doppler group, volume optimization was guided by the stroke volume changes in accordance with published protocols [14, 15]. Following an initial Doppler measurement, a fluid bolus was given and a new Doppler measurement was performed 5 min later. Fluid boluses were repeated until the stroke volume no longer increased by $10 \%$. The $10 \%$ cut-off value is commonly used in studies involving the esophageal Doppler, and is based on measurement characteristics of the device [16]. During surgery, additional optimizations were undertaken in the same way whenever the stroke volume had decreased by $\geq 10 \%$.

\section{Clinical outcome}

Two blinded observers retrospectively documented complications during the first 30 days after surgery using a pre-specified list of complications adapted from Brandstrup et al. [17] (see Additional file 1). A telephone call from the research nurse after postoperative day 30 supplemented the information from the electronic patient chart. If patients received care at another hospital during the 30 day period, copies of relevant reports were requested. Each observer independently scored complications; differences were resolved by discussion.

Length of hospital stay was defined as the number of calendar days spent in hospital, from the day of primary surgery until the 30th postoperative day. In case of in-hospital death within the observation period, a length of stay of 31 days was assumed.

\section{Statistical analysis}

In order to calculate a sample size that would be sufficient also for the secondary endpoint postoperative complications, we used combined data from the intervention arms of five previous studies on GDFT during abdominal surgery [18-22]. An expected total of 55 complications per 100 patients with a standard deviation of 19 was calculated. With a power of $90 \%$ and a significance level of 5\%, 66 patients would need to be included in each group to be able to demonstrate an absolute difference of $10 \%$ in postoperative complications [23]. Allowing for dropouts it was decided to include 150 patients in the study. Analysis was done on an intention to treat basis. Between groups differences were analyzed using Student T-test, Mann-Whitney U-test, Fisher's Exact test and chi-square test as appropriate using Statistica, versions 12 and 13 (Dell Incorporated, Tulsa, Oklahoma, USA). A $p$-value $<0.05$ was considered significant.

\section{Results}

Patients were recruited between November 14, 2011 and December 8, 2014, and the follow up of the last patient ended on January 8, 2015. A CONSORT flow diagram is presented in Fig. 1. After exclusion of four patients 146 were available for analysis.

Patient and surgical characteristics are presented in Table 1. Median duration of surgery was $3 \mathrm{~h}$ in both groups, with some procedures lasting more than $12 \mathrm{~h}$. Types of surgery are specified in Additional file 2.

In two patients in the PVI group (one with increasing lactic acidosis and one with continuing hemodynamic instability), in which the PVI indicated no need for further fluids, Doppler data were requested by the responsible anesthetist. These data confirmed an adequate fluid status, and the Doppler data were blinded for the rest of the procedure. These patients remained in the PVI group for the intention to treat analysis.

There were no differences between the groups in the amounts of colloids used during the optimizations, or in any other intraoperative fluid parameters (Table 2), with 


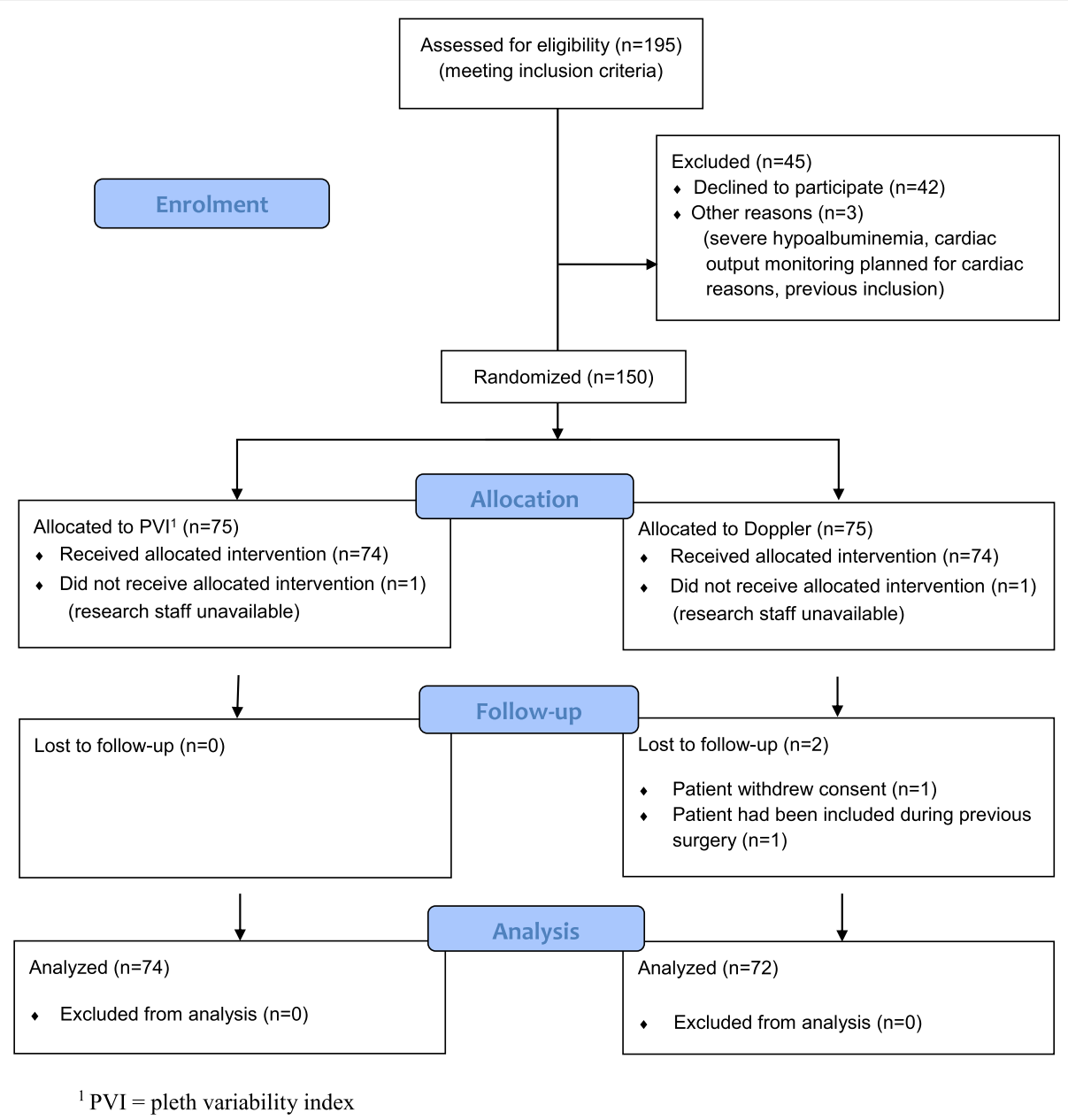

Fig. 1 CONSORT 2010 Flow Diagram

the exception of phenylephrine slightly more often being used in the PVI group $(P=0.04)$. Mean increase in body weight 1 day after surgery was $1.3 \mathrm{~kg}$ (SD 2.4) in the PVI group and $1.3 \mathrm{~kg}(\mathrm{SD} 1.7)$ in the Doppler group $(P=0.97)$.

\section{Postoperative complications and length of hospital stay}

There was no mortality during the study period. There were in total 64 complications in the PVI group $(n=74)$ and 70 in the Doppler group $(n=72)(P=0.93)$, corresponding to $38(51 \%)$ patients in the PVI group and 35 (49\%) patients in the Doppler group $(P=0.74)$ having had at least one complication (Table 3). Eleven complications necessitated surgical intervention requiring general anesthesia (three in the PVI group and eight in the Doppler group $(P=0.55))$ and in each group two complications required admission to the intensive care unit. Median length of hospital stay was 8.0 days (IQR 8.0) in the PVI group and 8.0 days (IQR 9.5) in the Doppler group $(P=0.57)$.

\section{Discussion}

There were no differences in the number of postoperative complications or length of hospital stay when GDFT was guided by PVI instead of esophageal Doppler during major open abdominal surgical procedures.

Previous studies show that both length of stay and incidence of complications were reduced when PVI was used as a part of a colorectal surgery multimodal enhanced recovery protocol in 109 patients, compared to historical controls [24]. The use of PVI also decreased perioperative lactate levels compared to controls $[6,25]$. Warnakulasuriya et al. [8] reported no difference in short term outcome when PVI was compared to esophageal Doppler in 40 patients. Based on these reports and our findings, a clinician wishing to pursue GDFT can choose PVI over esophageal Doppler in the large majority of patients undergoing major open abdominal surgery. PVI, in contrast to esophageal Doppler, is not sensitive to interference from diathermy and does not require frequent access to the patient's head for probe 
Table 1 Patient characteristics and perioperative data

\begin{tabular}{|c|c|c|}
\hline & $\begin{array}{l}\mathrm{PVI} \\
(n=74)\end{array}$ & $\begin{array}{l}\text { Doppler } \\
(n=72)\end{array}$ \\
\hline Age, mean (SD), years & $63(12)$ & $61(14)$ \\
\hline Female, n (\%) & $40(54)$ & $47(65)$ \\
\hline Body mass index, mean (SD), $\mathrm{kg} \mathrm{m}^{-2}$ & $26.0(4.1)$ & $26.7(6.3)$ \\
\hline \multicolumn{3}{|l|}{ ASA class } \\
\hline ASA 1, n (\%) & $22(30)$ & $27(38)$ \\
\hline ASA 2, n (\%) & $42(57)$ & $37(51)$ \\
\hline ASA 3, n (\%) & $10(13)$ & $8(11)$ \\
\hline \multicolumn{3}{|l|}{ Concomitant morbidity } \\
\hline Smoker, n (\%) & $14(19)$ & $8(11)$ \\
\hline Cardiovascular disease, n (\%) & $31(42)$ & $22(31)$ \\
\hline Neurological disease, n (\%) & $4(5)$ & $2(3)$ \\
\hline Diabetes, n (\%) & $11(15)$ & $8(11)$ \\
\hline \multicolumn{3}{|l|}{ Type of surgery } \\
\hline Gynecology, n (\%) & $23(31)$ & $19(26)$ \\
\hline Upper gastrointestinal, n (\%) & $18(24)$ & $26(36)$ \\
\hline Lower gastrointestinal, n (\%) & $22(30)$ & $21(29)$ \\
\hline Urology, n (\%) & $11(15)$ & $6(9)$ \\
\hline Enhanced recovery program, n (\%) & $7(9)$ & $8(11)$ \\
\hline Duration of surgery, median $\{\mid \mathrm{QR}\}, \mathrm{h}$ & $2.9\{2.2\}$ & $3.0\{2.2\}$ \\
\hline Duration of anesthesia, median $\{\mid \mathrm{QR}\}, \mathrm{h}$ & $4.1\{2.3\}$ & $3.9\{2.3\}$ \\
\hline Epidural, n (\%) & $66(89)$ & $67(93)$ \\
\hline $\begin{array}{l}\text { Lowest temperature during surgery, } \\
\text { mean (SD), }{ }^{\circ} \mathrm{C}\end{array}$ & $35.7(0.5)$ & $35.7(0.6)$ \\
\hline $\begin{array}{l}\text { Temperature end of surgery, } \\
\text { mean (SD), }{ }^{\circ} \mathrm{C}\end{array}$ & $36.4(0.6)$ & $36.4(0.6)$ \\
\hline
\end{tabular}

repositioning. Also, PVI can be measured without single-use equipment avoiding the cost for single-use esophageal probes (USD 130 in our setting). However, as illustrated by the request for Doppler data in two PVI patients, the clinician might still want to have access to a reliable method for measuring intraoperative cardiac output to increase the amount of hemodynamic information during unusually complex situations or in cases of known vascular and/or myocardial dysfunction. Data on cardiac output and thus contractility, systemic vascular resistance and oxygen delivery were available in the Doppler group but not incorporated in the treatment protocol, and decisions about inotropic and/or vasoactive support in both groups were left to the clinical judgement of the responsible anesthetist. Despite the more extensive hemodynamic information in the Doppler group, beside more use of the vasopressor phenylephrine in the PVI group, the amount of inotropic support did not differ between the treatment groups.

Other non-invasive methods for dynamic monitoring are available. One meta-analysis reported the offline assessment of respiratory variation in pulse oximetry
Table $\mathbf{2}$ Intraoperative fluid data

\begin{tabular}{|c|c|c|c|}
\hline & $\begin{array}{l}\text { PVI } \\
(n=74)\end{array}$ & $\begin{array}{l}\text { Doppler } \\
(n=72)\end{array}$ & $P$ \\
\hline $\begin{array}{l}\text { Crystalloid fluid, } \\
\text { mean (SD), ml }\end{array}$ & $1360(749)$ & $1240(662)$ & 0.31 \\
\hline $\begin{array}{l}\text { Total colloid fluid, } \\
\text { mean (SD), ml }\end{array}$ & $1464(1000)$ & $1412(1259)$ & 0.92 \\
\hline $\begin{array}{l}\text { Colloid during induction, } \\
\text { mean (SD), ml }\end{array}$ & $173(145)$ & $154(137)$ & 0.40 \\
\hline $\begin{array}{l}\text { Colloid used during } \\
\text { optimizations, mean (SD), ml }\end{array}$ & $675(434)$ & $665(462)$ & 0.89 \\
\hline $\begin{array}{l}\text { Synthetic colloid fluid, } \\
\text { mean (SD), ml }\end{array}$ & $1159(507)$ & $1141(532)$ & 0.84 \\
\hline Albumin 5\%, n (range, ml) & $14(120-1250)$ & $8(170-500)$ & 0.25 \\
\hline Albumin $20 \%, \mathrm{n}$ (range, $\mathrm{ml}$ ) & $8(100-200)$ & $6(45-100)$ & 0.78 \\
\hline Red blood cells, n (range, ml) & $10(280-1389)$ & $8(265-2310)$ & 0.80 \\
\hline Plasma, n (range, ml) & $6(776-2734)$ & $5(265-3300)$ & 1.00 \\
\hline Thrombocytes, n (range, ml) & 0 & $2(230-250)$ & 0.24 \\
\hline Phenylephrine, n (range, $\mu \mathrm{g}$ ) & $51(360-3928)$ & $37(240-6640)$ & 0.04 \\
\hline Norepinephrine, $\mathrm{n}$ (range, $\mu \mathrm{g}$ ) & $29(52-2180)$ & $30(11-2726)$ & 0.76 \\
\hline Dobutamine, n (range, mg) & $20(2-110)$ & $20(1-97)$ & 0.92 \\
\hline Blood loss, median $\{\mid \mathrm{QR}\}, \mathrm{ml}$ & $250\{500\}$ & $225\{487\}$ & 0.41 \\
\hline Urine, median $\{\mid \mathrm{QR}\}, \mathrm{ml}$ & $300\{326\}$ & $225\{310\}$ & 0.22 \\
\hline
\end{tabular}

Statistical differences were analyzed using Student T-test, Mann-Whitney U-test, chi-square test or Fisher's Exact test as appropriate. Significant results in bold

plethysmographic waveform amplitude $(\triangle \mathrm{POP})$ for predicting fluid responsiveness to be comparable to that of PVI (AUC 0.89 vs 0.95), but this technique is as yet not available in real time [26]. Also, pulse pressure variation and stroke volume variation can now be obtained non-invasively using the Nexfin/Clearsight ${ }^{\mathrm{TM}}$ or the $\mathrm{CNAP}^{\mathrm{TM}}$ systems, but their capacity for predicting fluid responsiveness differs between studies [27-30]. The same applies to measurements of the variability of the diameter of the caval vein or other veins during positive pressure ventilation [31]. Contrary to PVI, the effect on clinical outcome of all these techniques has to the best of our knowledge not been studied.

PVI is a dynamic indicator of fluid responsiveness based on cardiopulmonary interaction while stroke volume optimization is not. As both methods are claimed to be of benefit for fluid management, we argue that these methods, though differing in concept, can be compared with each other in a randomized trial focusing on clinical outcome [3]. Maintaining a patient below a certain PVI value might appear to be less aggressive then aiming for the plateau of the Starling curve, but this depends on the selected cut-off values. Probably, a higher cut off value for PVI with the same settings (such as tidal volume) would have resulted in less fluid administration and vice versa. We have previously shown that a PVI value of $10.5 \%$ was optimal in this material [9]. 
Table 3 Postoperative complications within 30 days after surgery

\begin{tabular}{|c|c|c|c|}
\hline & $\begin{array}{l}\text { PVI } \\
(n=74)\end{array}$ & $\begin{array}{l}\text { Doppler } \\
(n=72)\end{array}$ & \\
\hline \multicolumn{4}{|l|}{ Major } \\
\hline Anastomotic insufficiency & 3 & 1 & \\
\hline Lymphatic leakage & 0 & 0 & \\
\hline Bleeding & 0 & 1 & \\
\hline Sepsis & 0 & 1 & \\
\hline Wound dehiscence & 0 & 5 & \\
\hline Intestinal obstruction & 0 & 1 & \\
\hline Stroke & 0 & 0 & \\
\hline Pulmonary embolism & 0 & 0 & \\
\hline Deep vein thrombosis & 1 & 1 & \\
\hline $\begin{array}{l}\text { Pulmonary edema/ respiratory } \\
\text { insufficiency/ pneumonia }\end{array}$ & 1 & 2 & \\
\hline Pleural effusion & 0 & 5 & \\
\hline Myocardial infarction & 1 & 0 & \\
\hline Arrhythmia & 1 & 2 & \\
\hline Cardiac arrest & 0 & 0 & \\
\hline Renal dysfunction & 13 & 10 & \\
\hline Liver dysfunction & 0 & 0 & \\
\hline Total & 20 & 29 & \\
\hline \multicolumn{4}{|l|}{ Minor } \\
\hline $\begin{array}{l}\text { Superficial wound infection } \\
\text { or dehiscence }\end{array}$ & 6 & 4 & \\
\hline Infection & 10 & 11 & \\
\hline Paralytic ileus & 1 & 0 & \\
\hline Upper Gl bleeding & 0 & 1 & \\
\hline Pulmonary congestion & 5 & 0 & \\
\hline Angina pectoris & 1 & 1 & \\
\hline Hypotension & 2 & 6 & \\
\hline Delirium & 1 & 1 & \\
\hline Coagulopathy & 4 & 3 & \\
\hline $\begin{array}{l}\text { Severe postoperative } \\
\text { nausea and vomiting }\end{array}$ & 8 & 9 & \\
\hline Urinary retention & 6 & 5 & \\
\hline Total & 44 & 41 & \\
\hline Total number of complications & 64 & 70 & $(P=0.93)$ \\
\hline $\begin{array}{l}\text { Number (\%) of patients } \\
\text { with complications }\end{array}$ & $38(51)$ & $35(49)$ & $(P=0.74)$ \\
\hline $\begin{array}{l}\text { Mean number of complications } \\
\text { in patients with complications }\end{array}$ & 1.7 & 2.0 & $(P=0.28)$ \\
\hline
\end{tabular}

Statistical differences were analyzed using Mann-Whitney U-test or chi-square test as appropriate

\section{Limitations}

Limitations of this study include the absence of a control group without either PVI or Doppler to guide volume optimization. Early reports on stroke volume optimization using the esophageal Doppler were favorable [32]. Since then the technique has been questioned, partly because of negative studies on GDFT involving esophageal Doppler [33] and other devices [34, 35], and partly because of questions raised about the Doppler method itself [36]. Based on our results, it is not possible to tell whether PVI and Doppler both result in similar improvements in outcome, or whether neither method improves outcome when compared to treatment without GDFT. Such a control group was reflected upon at the time of designing the study (2011), but deemed unethical since, based on the evidence available at that time, we felt there was no equipoise about the benefits of GDFT. Equipoise about the use of GDFT is supported by our findings previously reported about the limited ability of both PVI and Doppler to predict fluid responsiveness [9]. Also protocol compliance, in terms of time during surgery with achieved PVI and SV goals respectively, was not recorded.

The amount of fluid used during the optimizations represents a part of the total fluid given, because of the per protocol complementary colloid fluid administration during the induction of anesthesia and for bleeding, and crystalloid fluid for maintenance and for the correction of preoperative dehydration. This increased the possibility that both groups would receive similar amounts of fluid; however, we did not find a difference between the groups in the amount of colloids used specifically for the optimizations.

We selected a difference of $10 \%$ in number of complications at 30 days to determine required sample size. Therefore the study was not powered to detect smaller albeit still significant differences in postoperative outcome. Also, it could be discussed whether a non-inferiority approach would have been more adequate. This would entail a larger required sample size.

The studies which were used to determine sample size scored complications in different ways and reported incidences of complications which are higher than can be expected in current practice using improved surgical and anesthetic techniques. The findings of this study cannot be applied to laparoscopic surgery. The majority of patients, although undergoing major surgery, were classified as ASA 1 or 2. The potential of GDFT to improve postoperative outcome is more pronounced in patients at higher risk of complications [37], and this could have influenced the possibility to find differences in outcome between the methods. Also, since intraoperative blood pressure is correlated to postoperative outcome, a target MAP should have been specified in the protocol.

Since the reliability of dynamic parameters including PVI increases with increasing tidal volume, a tidal volume of $8 \mathrm{ml} \mathrm{kg}^{-1}$ (ideal or actual body weight) or more is often recommended [38]. However, as large tidal 
volumes are probably detrimental in surgical patients [39] we, in line with earlier reports evaluating PVI, chose a tidal volume of $7 \mathrm{ml} \mathrm{kg}^{-1}$ ideal body weight $[6,7,13]$. Whether or not outcome is improved by using larger tidal volumes in surgical patients monitored with dynamic parameters is unknown.

\section{Conclusions}

We found no differences regarding number of postoperative complications or length of hospital stay between using PVI or esophageal Doppler for goal directed fluid therapy. PVI appears to be an acceptable alternative to esophageal Doppler for goal directed fluid therapy during major open abdominal surgery.

\section{Additional files}

Additional file 1: Definition of complications. Description of the criteria applied when scoring complications. (DOCX $18 \mathrm{~kb}$ )

Additional file 2: Types of surgery. List of surgical procedures performed during the study. (DOCX $16 \mathrm{~kb}$ )

\begin{abstract}
Abbreviations
ASA: American Society of Anesthesiologists; CONSORT: Consolidated standards of reporting trials; ECG: Electrocardiogram; GDFT: Goal-directed fluid therapy; IQR: Interquartile range; LBBB: Left bundle branch block; MAP: Mean arterial pressure; $\mathrm{PaCO}_{2}$ : Partial pressure of carbon dioxide in arterial blood; PaO2/FiO2: Ratio of partial pressure of oxygen in arterial blood divided by fraction of inspired oxygen; PT (INR): Prothrombin time (international normalized ratio); PVI: Pleth variability Index; SD: Standard deviation
\end{abstract}

\section{Acknowledgements}

We are indebted to research nurses Susanne Lind CRNA and Gunilla Gagnö CRNA, Department of Anesthesiology and Intensive Care, University Hospital Linköping, for their assistance with data collection.

\section{Funding}

This work was supported by the Department of Anesthesiology and Intensive Care, University Hospital Linköping, Sweden, and Region Östergötland. These organizations did not have any influence on study design, data collection and analysis and the submission process.

\section{Availability of data and materials}

The datasets used and/or analyzed during the current study are available from the corresponding author on reasonable request.

\section{Authors' contributions}

HB helped conduct the study, collect and analyze data and write the manuscript. RGH helped design the study, analyze data and write the manuscript. LN helped design the study, conduct the study, collect and analyze data and write the manuscript. All the authors read and approved the final manuscript.

\section{Ethics approval and consent to participate}

Ethical approval was obtained from the Regional Ethical Review Board in Linköping in March 2011 (2011/101-31), as was written informed consent from all included patients.

\section{Consent for publication}

Not applicable

\section{Competing interests}

RGH has given paid lectures for Baxter Healthcare. HB and LN declare that they have no competing interests.

\section{Publisher's Note}

Springer Nature remains neutral with regard to jurisdictional claims in published maps and institutional affiliations.

\section{Author details}

${ }^{1}$ Department of Medical and Health Sciences, Linköping University, University Hospital, 58185 Linköping, Sweden. ${ }^{2}$ Department of Anesthesiology and Intensive Care, Linköping University, University Hospital, 58185 Linköping, Sweden. ${ }^{3}$ Department of Medical and Health Sciences, Linköping University and Research Unit, Södertälje Hospital, 15286 Södertälje, Sweden.

Received: 12 November 2017 Accepted: 13 August 2018

Published online: 18 August 2018

\section{References}

1. Thacker JK, Mountford WK, Ernst FR, Krukas MR, Mythen MM. Perioperative fluid utilization variability and association with outcomes: considerations for enhanced recovery efforts in sample US surgical populations. Ann Surg. 2016;263:502-10.

2. Grocott MP, Dushianthan A, Hamilton MA, Mythen MG, Harrison D, Rowan K. Perioperative increase in global blood flow to explicit defined goals and outcomes after surgery: a Cochrane systematic review. Br J Anaesth. 2013; 111:535-48.

3. Benes J, Giglio M, Brienza N, Michard F. The effects of goal-directed fluid therapy based on dynamic parameters on post-surgical outcome: a metaanalysis of randomized controlled trials. Crit Care. 2014;18:e584.

4. Vincent JL, Pelosi P, Pearse R, Payen D, Perel A, Hoeft A, Romagnoli S, Ranieri VM, Ichai $C$, Forget $P$, et al. Perioperative cardiovascular monitoring of high-risk patients: a consensus of 12. Crit Care. 2015;19:e224.

5. Sondergaard S. Pavane for a pulse pressure variation defunct. Crit Care. 2013;17:e327.

6. Forget $\mathrm{P}$, Lois F, de Kock M. Goal-directed fluid management based on the pulse oximeter-derived pleth variability index reduces lactate levels and improves fluid management. Anesth Analg. 2010;111:910-4.

7. Forget $\mathrm{P}$, Lois F, Kartheuser A, Leonard D, Remue C, De Kock M. The concept of titration can be transposed to fluid management. But does it change the volumes? Randomised trial on pleth variability index during fast-track colonic surgery. Curr Clin Pharmacol. 2013;8:110-4.

8. Warnakulasuriya SR, Davies SJ, Wilson RJT, Yates DRA. Comparison of esophageal Doppler and plethysmographic variability index to guide intraoperative fluid therapy for low-risk patients undergoing colorectal surgery. J Clin Anesth. 2016;34:600-8.

9. Bahlmann $\mathrm{H}$, Hahn RG, Nilsson L. Agreement between Pleth variability index and oesophageal Doppler to predict fluid responsiveness. Acta Anaesthesiol Scand. 2016;60:183-92.

10. Hahn RG, Bahlmann H, Nilsson L. Dehydration and fluid volume kinetics before major open abdominal surgery. Acta Anaesthesiol Scand. 2014;58: 1258-66.

11. Predicted body weight calculator. http://www.ardsnet.org/tools.shtml. Accessed 16 June 2017.

12. Quantitative skills. Random allocator. http://www.quantitativeskills.com/sisa/ calculations/randmiz.htm. Accessed 16 June 2017. (Originally accessed at URL: http://home.clara.net/sisa/randmiz.htm).

13. Zimmermann M, Feibicke $T$, Keyl C, Prasser C, Moritz S, Graf BM, Wiesenack C. Accuracy of stroke volume variation compared with pleth variability index to predict fluid responsiveness in mechanically ventilated patients undergoing major surgery. Eur J Anaesthesiol. 2010;27:555-61.

14. Challand C, Struthers R, Sneyd JR, Erasmus PD, Mellor N, Hosie KB, Minto G. Randomized controlled trial of intraoperative goal-directed fluid therapy in aerobically fit and unfit patients having major colorectal surgery. $\mathrm{Br} J$ Anaesth. 2012;108:53-62.

15. Jørgensen CC, Bundgaard-Nielsen M, Skovgaard LT, Secher NH, Kehlet H. Stroke volume averaging for individualized goal-directed fluid therapy with oesophageal Doppler. Acta Anaesthesiol Scand. 2009;53:34-8.

16. Deltex Medical. Accuracy \& Precision. http://www.deltexmedical.com/ cardioq-odm/accuracy-precision. Accessed 16 June 2017.

17. Brandstrup $B$, Tønnesen $H$, Beier-Holgersen R, Beier-Holgersen R, Hjortsø $E_{\text {, }}$ Ørding H, Lindorff-Larsen K, Rasmussen MS, Lanng C, Wallin L, et al. Effects of intravenous fluid restriction on postoperative complications: comparison of two perioperative fluid regimens. Ann Surg. 2003;238:641-8. 
18. Noblett SE, Snowden CP, Shenton BL, Horgan AF. Randomized clinical trial assessing the effect of Doppler-optimized fluid management on outcome after elective colorectal resection. Br J Surg. 2006;93:1069-76.

19. Wakeling $H G$, McFall MR, Jenkins CS, Woods WG, Miles WF, Barclay GR, Fleming SC. Intraoperative oesophageal Doppler guided fluid management shortens postoperative hospital stay after major bowel surgery. $\mathrm{Br} \mathrm{J}$ Anaesth. 2005;95:634-42.

20. Gan TJ, Soppitt A, Maroof M, el-Moalem H, Robertson KM, Moretti E, Dwane P, Glass PS. Goal-directed intraoperative fluid administration reduces length of hospital stay after major surgery. Anesthesiology. 2002;97:820-6.

21. Mayer J, Boldt J, Mengistu AM, Röhm KD, Suttner S. Goal-directed intraoperative therapy based on autocalibrated arterial pressure waveform analysis reduces hospital stay in high-risk surgical patients: a randomized, controlled trial. Crit Care. 2010;14:e18.

22. Benes J, Chytra I, Altmann P, Hluchy M, Kasal E, Svitak R, Pradl R, Stepan M. Intraoperative fluid optimization using stroke volume variation in high risk surgical patients: results of prospective randomized study. Crit Care. 2010;14:e118.

23. Faul F, Erdfelder $E$, Lang A-G, Buchner A. G*Power 3: a flexible statistical power analysis program for the social, behavioral, and biomedical sciences. Behav Res Methods. 2007;39:175-91.

24. Thiele RH, Rea KM, Turrentine FE, Friel CM, Hassinger TE, McMurry TL, Goudreau BJ, Umapathi BA, Kron IL, Sawyer RG, et al. Standardization of care: impact of an enhanced recovery protocol on length of stay, complications, and direct costs after colorectal surgery. J Am Coll Surg. 2015;220:430-43.

25. Yu Y, Dong J, Xu Z, Shen H, Zheng J. Pleth variability index-directed fluid management in abdominal surgery under combined general and epidural anesthesia. J Clin Monit Comput. 2015;29:47-52.

26. Sandroni C, Cavallaro F, Marano C, Falcone C, De Santis P, Antonelli M. Accuracy of plethysmographic indices as predictors of fluid responsiveness in mechanically ventilated adults: a systematic review and meta-analysis. Intensive Care Med. 2012;38:1429-37.

27. de Wilde RB, de Wit F, Geerts BF, van Vliet AL, Aarts LP, Vuyk J, Jansen JR. Non-invasive continuous arterial pressure and pulse pressure variation measured with Nexfin in patients following major upper abdominal surgery: a comparative study. Anaesthesia. 2016;71:788-97.

28. Stens J, Oeben J, Van Dusseldorp AA, Boer C. Non-invasive measurements of pulse pressure variation and stroke volume variation in anesthetized patients using the Nexfin blood pressure monitor. J Clin Monit Comput. 2016;30:587-94.

29. Monnet X, Dres M, Ferré A, Le Teuff G, Jozwiak M, Bleibtreu A, Le Deley MC, Chemla D, Richard C, Teboul JL. Prediction of fluid responsiveness by a continuous non-invasive assessment of arterial pressure in critically ill patients: comparison with four other dynamic indices. Br J Anaesth. 2012;109:330-8.

30. Biais M, Stecken L, Martin A, Roullet S, Quinart A, Sztark F. Automated, continuous and non-invasive assessment of pulse pressure variations using CNAP ${ }^{\circledR}$ system. J Clin Monit Comput. 2017;31:685-92.

31. de Oliveira OH, Freitas FG, Ladeira RT, Fischer CH, Bafi AT, Azevedo LC, Machado FR. Comparison between respiratory changes in the inferior vena cava diameter and pulse pressure variation to predict fluid responsiveness in postoperative patients. J Crit Care. 2016;34:46-9.

32. Phan TD, Ismail H, Heriot AG, Ho KM. Improving perioperative outcomes: fluid optimization with the esophageal Doppler monitor, a meta-analysis and review. J Am Coll Surg. 2008;207:935-41.

33. Brandstrup $B$, Svendsen PE, Rasmussen M, Belhage B, Rodt $S \AA$, Hansen $B$, Møller DR, Lundbech LB, Andersen N, Berg V, et al. Which goal for fluid therapy during colorectal surgery is followed by the best outcome: nearmaximal stroke volume or zero fluid balance? Br J Anaesth. 2012;109:191-9.

34. Pearse RM, Harrison DA, MacDonald N, Gillies MA, Blunt M, Ackland G, Grocott MP, Ahern A, Griggs K, Scott R, et al.; OPTIMISE study group. Effect of a perioperative, cardiac output-guided hemodynamic therapy algorithm on outcomes following major gastrointestinal surgery: a randomized clinical trial and systematic review. JAMA 2014;311:2181-2190.

35. Pestaña D, Espinosa E, Eden A, Nájera D, Collar L, Aldecoa C, Hiquera E, Escribano S, Bystritski D, Pascual J, et al. Perioperative goal-directed hemodynamic optimization using noninvasive cardiac output monitoring in major abdominal surgery: a prospective, randomized, multicenter, pragmatic trial: POEMAS study (PeriOperative goal-directed thErapy in major abdominal surgery). Anesth Analg. 2014;119:579-87.
36. Minto G, Struthers R. Stroke volume optimisation: is the fairy tale over? Anaesthesia. 2014;69:291-6.

37. Cecconi M, Corredor C, Arulkumaran N, Abuella G, Ball J, Grounds RM, Hamilton M, Rhodes A. Clinical review: goal-directed therapy-what is the evidence in surgical patients? The effect on different risk groups. Crit Care. 2013;17:209.

38. Desebbe O, Boucau C, Farhat F, Bastien O, Lehot J-J, Cannesson M. The ability of pleth variability index to predict the hemodynamic effects of positive end-expiratory pressure in mechanically ventilated patients under general anesthesia. Anesth Analg. 2010;110:792-8.

39. Serpa Neto A, Hemmes SN, Barbas CS, Serpa Neto A, Hemmes SN, Barbas CS, Beiderlinden M, Biehl M, Binnekade JM, Canet J, et al. PROVE Network Investigators. Protective versus conventional ventilation for surgery: a systematic review and individual patient data meta-analysis. Anesthesiology 2015;123:66-78.

\section{Ready to submit your research? Choose BMC and benefit from:}

- fast, convenient online submission

- thorough peer review by experienced researchers in your field

- rapid publication on acceptance

- support for research data, including large and complex data types

- gold Open Access which fosters wider collaboration and increased citations

- maximum visibility for your research: over $100 \mathrm{M}$ website views per year

At BMC, research is always in progress.

Learn more biomedcentral.com/submissions 